\title{
Optimizing Engineering Project Governance for Sustainability
}

\author{
David Tuffley ${ }^{1,}$, , Yuk Kuen Wong ${ }^{2, b}$ and Luke Houghton ${ }^{3, c}$ \\ ${ }^{1}$ School of Information \& Communication Technology, Griffith University Nathan, Brisbane, Qld. \\ 4111, Australia \\ ${ }^{2}$ Department of Accounting \& Corporate Governance, Faculty of Business \& Economics, Macquarie \\ University, NSW 2109 Australia \\ ${ }^{3}$ Department of International Business \& Asian Studies, Griffith Business School, Griffith University, \\ Nathan, Brisbane, QLD, 4111, Australia

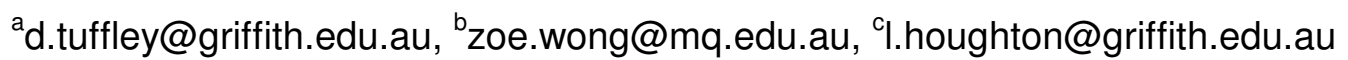

Keywords: sustainability, equity of access, international governance, process reference model, leadership, complex teams, virtual teams, process assessment model.

\begin{abstract}
Organisations are increasingly leveraging improved decision making processes during the establishment of project teams. Beyond the obvious advantages of accessing qualified, cost-effective project staff, the issues of sustainability and governance are addressed when the virtual teaming approach is used. Projects can proceed without people needing to travel to a co-located work-place, thus saving time, effort and expense while creating less environmental pollution. But there is a governance problem; running virtual projects, particularly complex projects involve a greater degree of difficulty than managing co-located projects. What is needed are effective, practical methods for managing virtual projects. This paper introduces a new Reference Model of Organisational Behavior (RMOB) for the Leadership of Complex Virtual Teams which is arguably an effective way to meet the challenges of virtual teaming. This paper also discusses the new issue of sustainable leadership with mention of the proposed Organisation for Economic Cooperation and Development (OECD) Management indicators that point towards sustainable governance.
\end{abstract}

\section{Introduction}

Advances in broadband internet technology can today deliver high definition video and audio at relatively low-cost. This makes it possible to leverage cost-effective labor around the world to work on development and maintenance projects. The age of the virtual worker has well and truly arrived [1].

While virtual teams have solved a number of organisational problems in the developed world (i.e. how to keep overheads to a minimum) it has broader benefits for the world at large, in particular for the developing world (those economically underdeveloped countries in the former "third world"). Virtual teaming and the associated governance model is therefore presented in the context of assisting developing countries to gain access to the labor markets of the developed world while simultaneously enabling more environmentally sustainable project management practices.

This paper explores the question; can the governance of virtual teams be optimized through the use of Reference Models of Organisational Behavior (RMOB). In our treatment of this main question, two subordinate questions will be discussed; (a) might the RMOB thus be a viable option for developing nations to reap the economic benefits of greater participation in the global economy, and (b) to do so in an environmentally sustainable way? Exploring this complex question contributes to the project management literature, particularly in relation to the governance of virtual teams, and the evolution of sustainable project management practices.

A virtual team can be described broadly as a group of people who perform their work using information and communication technology to bridge time, space, and organizational boundaries [2]. Virtual teaming reduces environment pollution through removing the need for people to travel to a workplace [3]. It is reasonable to conclude from this that there will be less carbon dioxide released 
into the atmosphere which would help mitigate the problem of greenhouse gas. These benefits contribute to a sustainable future.

The governance of virtual teams is a major challenge facing project managers [4]. Any project of any complexity will have its significant challenges in the efficient co-ordination of activities, but when complex projects are done by virtual teams the degree of difficulty is compounded due to the distributed nature of the team. Coupled with this are the dual streams of learning, action and interdependent processes [5], all of which all present real problems and challenges for virtual teams. To meet the challenge this paper proposes a Process Reference Model for the Leadership of Complex Virtual Teams.

While the Leadership model proposed in this paper has implications for the governance of projects and organisations, it also has wider implications. If Leadership can be described as a process and packaged into a model for process improvement purposes, then so can a wide variety of other behaviors that are nonetheless important but difficult to describe. A process-orientated approach is often used to link the underlying explicit or easily identifiable ICT components (i.e. Databases, Applications, Systems and Infrastructure) to the implicit or more intangible assets contained within a modern Organization (i.e. innovation, problem solving, culture, leadership and competencies / capabilities). A process orientated approach is therefore an appropriate way to explore the concept of Leadership.

This paper therefore explores Reference Models of Organizational Performance (RMOB) as a means to address this shortfall in our ability to adequately describe implicit concepts such as leadership within the Firm. RMOBs describe aspects of desired organisational behavior that if performed repeatedly will become institutionalised and which will result in consistently achieving the prescribed purpose. This approach re-focuses attention from conformance to prescribed activities and tasks, to a focus on the demonstration of desired organizational behavior, thereby taking us away from the traditional role of a Process Reference Model. RMOBs must conform to the criteria for Process Reference Models (of which RMOB's are a category). These criteria are prescribed in ISO/IEC 15504 [6] and ISO/IEC 24774 [7]. The leadership RMOB discussed in this paper conforms to these standards.

\section{Project Governance}

The role of project governance is to provide leadership and a decision making framework [8] that aligns the accountabilities and responsibilities associated with the organization's business activities with corporate governance in long term sustainability. This is a critical element of projects as it provides robust and repeatable frameworks to govern a company. The decision making framework is supported by three pillars - structure, people and information. The structure refers to project structure such as steering committee (board), stakeholders and process. An effective committee requires people and leadership. Information provides to people for effective decision making.

Garland [9] outlines the logical steps needed to establish a project governance framework for a project or organization. Beginning with the problems typical of ineffective project governance, Garland develops a set of principles designed to overcome these problems and builds a framework based on these principles (see Table 1 below).

Table 1: Four principles of project governance [9].

\section{Project Governance Principles}

Principle 1 Ensure a single point of accountability for the success of the project

Principle 2 Service delivery ownership determines project ownership

Principle Ensure separation of stakeholder management and 


\begin{tabular}{ll}
\hline $3:$ & project decision making activities \\
\hline Principle 4 & $\begin{array}{l}\text { Ensure separation of project governance and } \\
\text { organisational governance structures }\end{array}$ \\
\hline
\end{tabular}

It has been suggested [9] that an appropriate project governance framework is based around the four principles listed above in order to ensure effectiveness. A project requires effective leadership that provides clear understanding of accountability for its success [10]. Principles 1 and 2 focus on people, the key stakeholders such as the owner of the project. As a project has many stakeholders, therefore, an effective project governance framework provides necessary understanding of these stakeholders and addresses the key stakeholders' needs.

Principle 3 deals with the decision-making effectiveness of the project manager. Projects require effective decision making and an understanding of the hierarchical structuring [11] process that is associated with the organisational reporting structure. Project governance structures overcome this by drawing the key decision makers out of the company structure and developing a serial decision making process associated with hierarchies.

Sustainable Governance Performance Indicators. The Sustainable Governance Indicators (SGI) (OECD, 2009) analyzes and compares the need for reform in Organisation for Economic Co-operation and Development (OECD) member countries. It is also concerned with each country's ability to respond to current social and political challenges. Two majors SGIs [29]:

- Status index is based on quantitative and qualitative evaluation and measurements. This index has two dimensions. The first examines different categories including electoral process, access to information, civil rights and the rule of law of each country. The second dimension of the status index is about the correspondent to the OECD states such as economy, employment, security, social affairs, sustainability indicators and policies.

- Management index measures in relative terms a government's capability to achieve effective reform. There are two dimensions to this index. The first measures the problem solving capabilities and the strategic steering with respect to the OECD states. This allows us to analyze a government's structure and its process. The key measurements are (a) resources efficiency, (b) analytical categories, (c) international cooperation and (d) institute learning. The second dimension is the accountability of governance performance. This considers how the government interacts with their constituent parties and measures the influence of each party.

Sustainable governance can therefore be evaluated by these prescribed performance indicators (particularly in Management Index, e.g. Executives Capacity and Executives Accountability) [29], thus demonstrating that management and leadership is amenable to being described in terms of process. The next section explores further the question of how effectively can leadership be described as a process. The following models provide more details about the leadership in project process and how the leadership can improve the sustainable projects and governance according to the OECD definition.

\section{Can leadership be described as a process?}

Leadership is not alone in the broad category of behaviors engaged in by organisations as they pursue their objectives. If leadership can be described in a Process Reference Model (PRM) and supported by a Process Assessment Model, then theoretically so too might these other behaviors not yet serviced by a PRM. For example, ISO/IEC 15504 [6] gives organizations the means to develop and assess their integrated teaming capability against the measurement framework prescribed by ISO/IEC 15504 [6].

We begin by examining whether there are grounds to believe that PRMs are applicable in addressing leadership in a project environment? It will be seen from the discussion that PRMs and Model Based Process Improvement (MBPI) can arguably be applied to a range of software engineering challenges, including the challenge of project leadership. 
As seen in Figure 1, there are two broad justifying reasons; first that Leadership can be taught and learned by those who would practice it [12] [13] [14]. The second reason is that defining processes is necessary for organisational effectiveness[15]. As Deming said, if you cannot describe what you are doing as a process, then you don't know what you are doing [16].

Therefore, as a high-level proposition, there seems to be no good reason that since leadership can be taught/learned, and that any properly understood activity should be amenable to being described as a process, then leadership should be able to be described as a process (see Figure 1). Adopting the approach used in the Model-based Process Improvement sub-domain of Software Engineering research offers a practical, proven method for formalizing process models [6] [7]. More detail model is shown in Figure 2.

The conceptual overview diagram in Figures 1 and 2 illustrates the evolution of the process model approach. In Figure 2, it is indicated that there is a basic distinction between co-located and virtual teams, and that integrated teams can be either. Virtual teams do not have to be integrated but commonly are. Integrated teams do not have to be distributed, but commonly are. Therefore, the characteristics of successful teams and successful leaders are considered for both co-located and virtual teams, resulting in the characteristics of leaders of integrated teams operating in virtual environments.

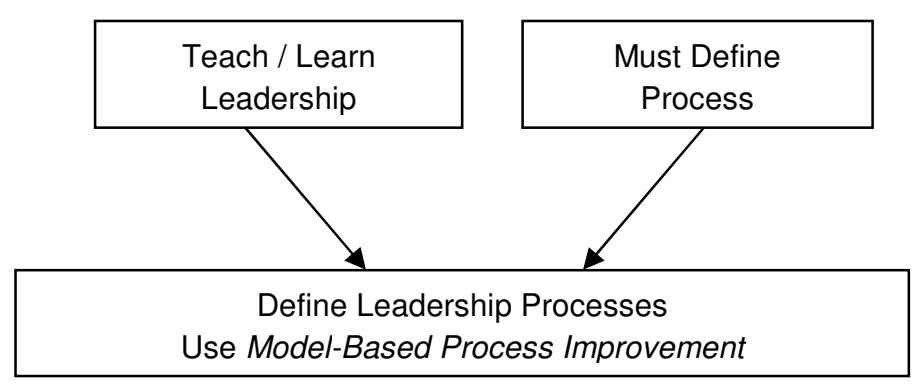

Figure 1. Model-Based Process Improvement enables definition of leadership processes The evolution of the process reference and assessment models is illustrated below: 


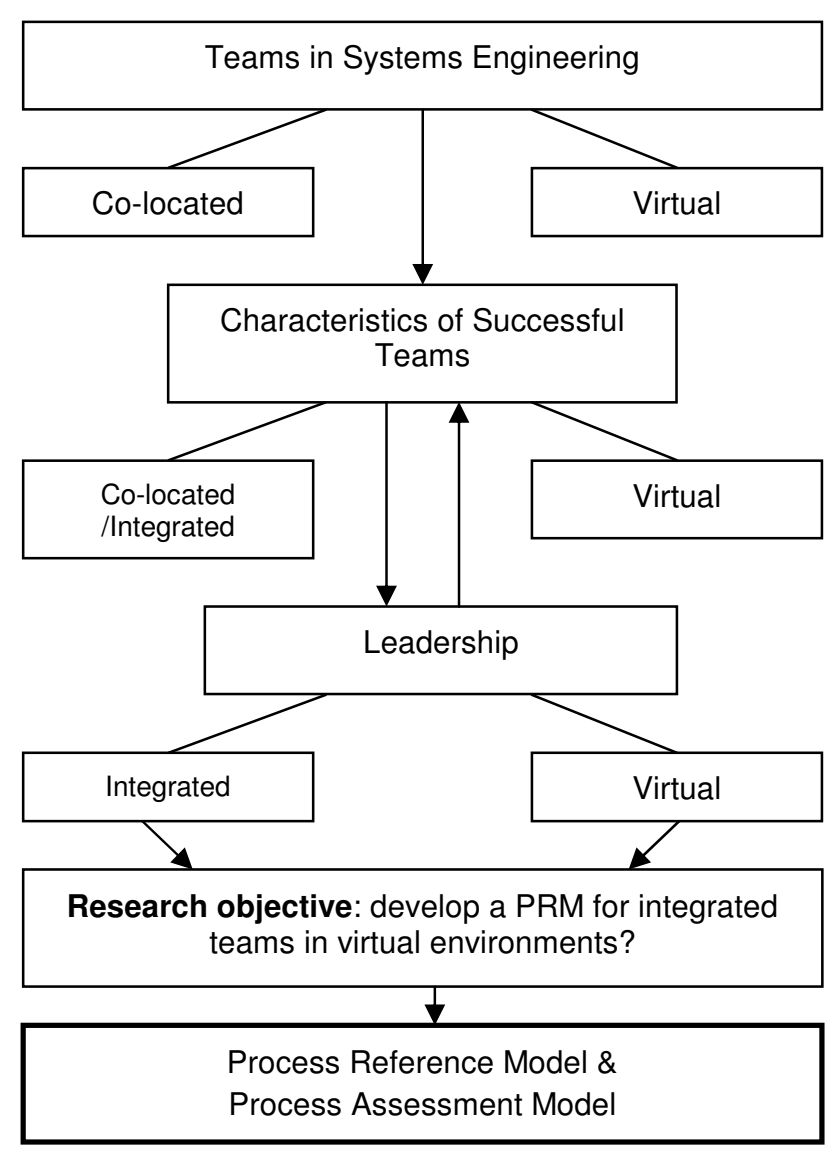

Figure 2. Conceptual overview of how Leadership PRM \& PAM evolved

\section{Process-oriented Leadership in Sustainability Management}

In the field of resource management, Taylor and Goldstein [17] emphasize the importance of building leadership capability in organisations seeking to promote more sustainable resource management practices. Leadership capability is seen as a key enabler of effective sustainability management. In Taylor's view, the leadership process has three broad phases.

- Phase 1 Initiation, where ideas from the sustainable project plan are formulated and elaborated.

- Phase 2 Endorsement, where project governance leaders or sponsors provide support and resources that are necessary for the implementation of the vision outlined in the previous phase.

- Phase 3 Implementation, where manager-leaders work together across the organisation to implement the project plan. This phase also includes critical inputs from all relevant stakeholders.

The leadership process usually begins with the individual vision of the leader, then proceeds to a more team-based approach. The Leadership Process Model outlined later in this paper is consistent with Taylor's broad approach [17] in the sense that it divides the Leadership Model into three distinct process areas (a) Individual, (b) team, and (c) organisation. The Leadership process begins with the Leader's internal attributes of vision, communication ability, integrity, resilience etc, then moves on to the practical aspects of team and organisational functioning for optimal outcomes.

This paper proposes to extend the view that leadership can be described as a broad process with phases to assert that it can be formalized into a process model. As Deming suggests if you can't describe what you are doing as a process, then you don't really know what you are doing [16].

Process-oriented Leadership Decision Making. Newell and Simon [18] originally argued that decision making is performed across a series of processes, or phases. This begins with the identification of the problem and the optimum decision-making strategy. Checkland [19] extended 
these ideas to argue that complex problem solving and decision making is open to what Linstone [20] later called multiple perspectives. The process of reaching the sustainable project plan is where leaders sift through alternative representations of a solution and reach a plan about what is considered feasible [19]. This is arguably part of the process that can't be captured because it is an inherent part of complex project formation and decision-making.

However, once consensus is reached on what action is to be taken, leadership becomes about managing through what was agreed upon [21]. Once the model is agreed upon or clearly defined notes, a process can effectively be put in place to manage the implementation process [21]. This means establishing parameters and being able, at least to some extent, to quantify the processes of leadership during project implementation.

The sub-domain of Software Engineering research known as Model-based Process Improvement offers a viable way forward.

\section{Model-Based Process Improvement as a solution to rising organizational complexity}

The business of managing complex projects across dispersed geographical locations has never been more difficult, given the rising complexity of the global economic environment and the multi-national corporate entities that now inhabit this world. There is a clear need to find improved ways of managing this often difficult process now and into the future [1].

Model Based Process Improvement (MBPI) potentially offers the means by which organisational challenges such as the leadership of complex virtual teams can be met. MBPI has not (to the knowledge of the author) been used to address leadership, though there is arguably a sound basis for thinking that it can be used in this way.

MBPI aims generally to improve the performance and maturity of an organization's processes. It combines the discipline of process improvement with the several international standards and frameworks now in use (i.e. ISO/IEC 15504, CMMI). Combining this awareness of process performance with internationally recognised standards is advantageous to organisations. It affords a structured and comprehensive framework as a way forward and prescribes in general terms the scope of activities required to systematically improve their process maturity.

Heston and Phifer [22] ascribe the following organisational benefits to MBPI:

- Improving consistency and repeatability: consistency and repeatability assist with minimizing process variation, a major source of product defects. It also allows project staff to move into and out of projects more easily by having clearly defined roles and responsibilities.

- Improving communication: achieved through the adoption of a common vocabulary with clearly prescribed meanings that allows project staff, clients and business partners to communicate with less ambiguity.

- Enabling more improvement: process improvement programs create an environment which is conducive to further improvement. Beyond consistency and repeatability comes the ability to measure and record process performance. This performance data can then be used to plan further improvements and to benchmark against best practice.

- Providing motivation: objective targets, for example being assessed at a certain level of maturity, become a visible motivator for project staff to maintain their efforts to improve process performance.

\section{Leadership PRM in practice}

The Leadership PRM was developed using a Design Research approach [23] [24] in which an initial prototype was developed based on the broad literature and reviewed in a series of design iterations over an 18 month period (a total of six reviews). The reviews included the standard PRM-developer's method of practitioner and expert reviewers, plus an ISO/IEC 24774 [7] conformance review to 
ensure the model met the requirements of that standard. The PRM was also validated with Dromey's Behavior Engineering [25], a formal method for checking content and syntax for errors and ambiguities that was developed initially for validating software requirements for complex systems, but which has proven a highly effective method for validating PRMs [26].

Having passed through these six reviews, the V1.0 PRM was released and reviewed again by a focus group over a full day. The group comprised two practitioner project managers and two experts on process models in software engineering. The terms of reference of this post-release review was to evaluate the efficacy of the leadership PRM, particularly in relation to (a) fitness for purpose, (b) organisation of and content of elements, and (c) what would make it more usable from a practitioner's point of view?

As a result of the review, V1.1 PRM was produced. This version incorporated the accumulated feedback from the focus group and resulted in substantial changes by (a) consolidating and merging several processes, (b) reordering the processes to reflect a sequence more naturally performed in projects, and (c) adding additional informative material relevant to virtual and/or integrated project environments. All of these changes were consistent with the review's terms of reference.

\section{Reference Model of Organisational Behavior}

The RMOB was developed using Design Research [24] in which multiple review iterations are performed on the developed artefact. The general methodology is adapted for this project as shown below:

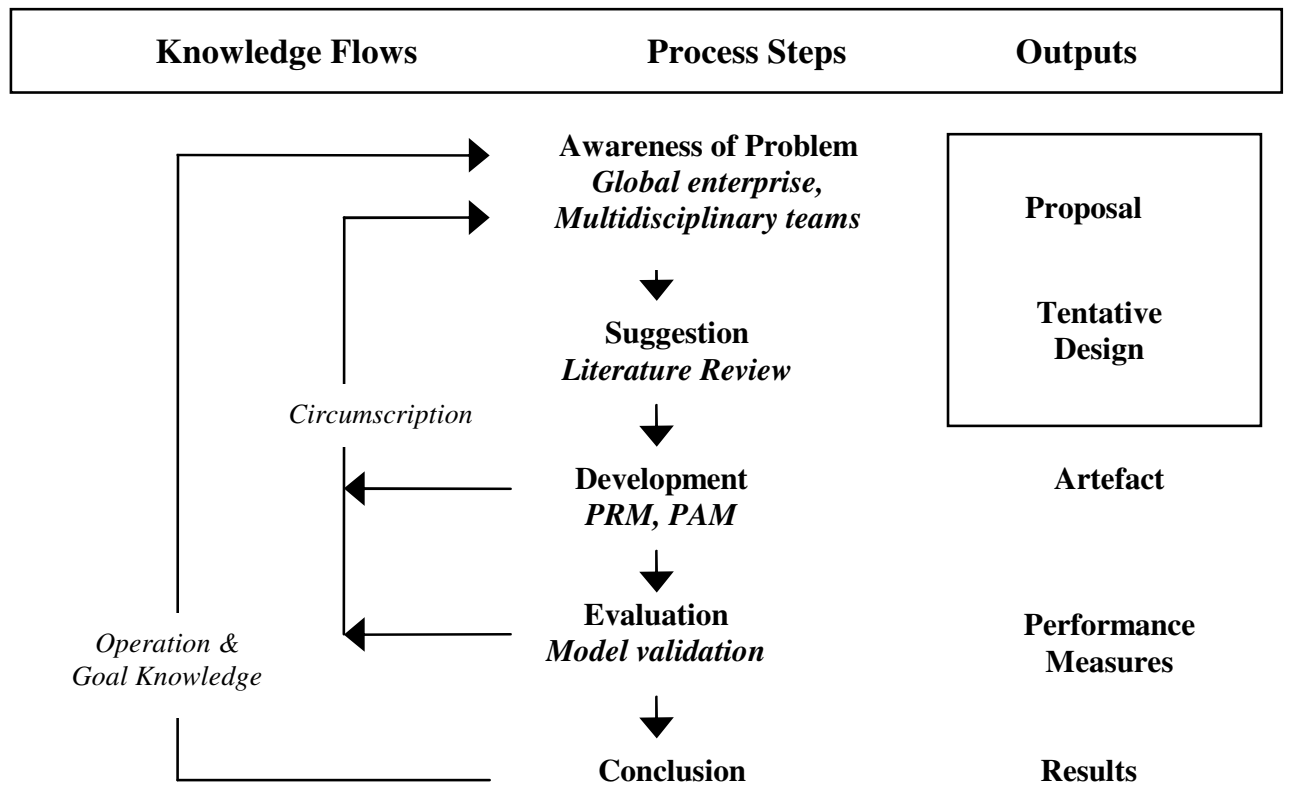

Figure 33: Methodology of Design Research for this project [27] [28].

Hevner [24] describes Design Research as a pragmatic research method, predicated on being relevant to real-world situations and making a clear contribution to the application environment. Hevner [24] describes Design Research as the embodiment of three inter-related cycles, these being the Relevance, Rigor and Design Cycles.

Data collection was by a focus group review that was aimed at improving the usefulness and usability of the model. The review was performed by a rigorous examination of the model over a six hour period by a focus group comprised of four project managers, each of whom were actively coordinating the activities of a virtual team. Two of the project managers were from the IT projects segment of the higher education sector; the other two were from the systems development segment of the Australian defense contractor sector. The group evaluated each process and associated outcomes 
for accuracy, understandability and comprehensiveness. For most outcomes, individual work products were identified and recorded. All data was collected and incorporated into Version 1.1 of the model.

The data from the focus group was recorded into a pro-forma, as shown in the table below. The data included objective evidence that an outcome is actually being performed, and suggested improvements to the wording and content of the model.

Table 2: Focus group data collection pro-forma (sample)

\subsection{Create and communicate a shared vision}

Purpose: to perceive and communicate a guiding principle/idea that captures the imagination of members to create a shared vision and inspire them with the enthusiasm to realise that vision. An aspect of charisma.

(Suggested change) Purpose: The purpose of the vision process is to create and communicate a shared vision in ways that inspires people to realize that vision

Outcomes: as a result of the successful implementation of creating a shared vision:

The leader perceives and formulates a unified vision of what is to be accomplished, ideally seen as an accomplished fact.

Activities and/or artefacts to support (bullet points are project manager's input $X 4)$ :

- Team Charter (Vision enunciated) Workshop

- Imperative objectives Website Comm thru mngt (Strategy -> Tactics

-> Implement

- Project plan, Project launch presentation

- Plan w Snr Management

Leader communicates shared unified vision with team, ideally seen as an accomplished fact.

Activities and/or artefacts to support:

- Vision statement, Roadmap

- Yearly kick-off Quarterly review

- Team briefing

- Regular project meetings goals restated

Leader develops strong commitment to achieving vision, based on a sense of rightness and timeliness, such that they have sufficient resilience to overcome goal frustrating events

Activities and/or artefacts to support:

- $\mathrm{n} / \mathrm{a}$

- $\mathrm{n} / \mathrm{a}$

- Through briefings

- Regular meetings

Importantly for the purposes of this paper, the clear consensus of the focus group was that the Leadership PRM would be a useful model for them to use. They each wanted a copy of the updated V1.1 PRM for use in their own projects, which they were duly given. This feedback lends support to the argument that a Reference Model of Organisational Behavior that conforms to the requirements of a PRM in a software engineering sense can be a useful and usable artefact for practicing project managers. 
Also emerging from this first post-release review was a Process Assessment Model (PAM) based on the Leadership PRM. This PAM was developed in accordance with ISO/IEC 15504-1:2004 Parts 1 and 2,

Table 3. Structure and content of Leadership Process Assessment Model.

\begin{tabular}{|c|c|}
\hline \multicolumn{2}{|c|}{ Leadership Process Assessment Model } \\
\hline \multicolumn{2}{|c|}{ Individual Process Group (IND) } \\
\hline IND.1 & Vision \\
\hline IND.2 & Objective(s) \\
\hline IND.3 & Integrity \\
\hline IND.4 & Action-orientation \\
\hline IND.5 & Intelligence \\
\hline IND.6 & Individualized consideration \\
\hline IND.7 & Management-by-exception \\
\hline \multicolumn{2}{|c|}{ Team Process Group (TEM) } \\
\hline TEM.1 & Team structure \\
\hline TEM.2 & Team requirements \\
\hline TEM.3 & Team recruitment \\
\hline TEM.4 & Team environment \\
\hline TEM.5 & Team formation \\
\hline TEM.6 & Team roles \\
\hline TEM.7 & Team rules \\
\hline TEM.8 & Team authority \\
\hline TEM.9 & Team performance management \\
\hline TEM.10 & Team development \\
\hline \multicolumn{2}{|c|}{ Organisation Process Group (ORG) } \\
\hline ORG.1 & Team boundaries \\
\hline ORG.2 & Team collaboration \\
\hline ORG.3 & Team \& home organization balance \\
\hline
\end{tabular}

An example process from the PAM (Vision) is shown in the table below. It and the other 15 processes have now been elaborated into a draft PAM. The first review established that a PAM which embodies at least the Process dimension is viable. The second and subsequent reviews (V1.2 onwards) will investigate the feasibility of including the Capability dimension in the Leadership PAM. While it has been established during the validation of the PRM that each of the outcomes can be substantiated by the presence of artefacts and/or activities, it is not yet clear whether the discernable process indicators can be distinguished with sufficient clarity to establish the capability dimension. Only by performing a number of assessments using the draft PAM and accumulating data in the Work Products / Activities / Conditions section will we know whether a capability dimension is feasible.

This work is on-going.

Table 4. Structure and content of PAM Example 1.

\begin{aligned} & \hline Process ID IND.1 \\ & \hline Process Name: Vision \\ & \hline Process Purpose: $\begin{array}{l}\text { The purpose of the vision process is to create and } \\ \text { communicate a shared vision in ways that inspires people to } \\ \text { realise that vision. }\end{array} \\ &$\hline\end{aligned}




\begin{tabular}{ll}
\hline Process Outcomes: & $\begin{array}{l}\text { As a result of successful implementation of the vision } \\
\text { process: }\end{array}$ \\
& 1) A vision of the goal(s) is created. \\
& 2) $\quad$ The vision of the goal(s) is communicated to the team \\
& 3) Commitment by team to the shared vision is gained \\
\hline Base Practices: & $\begin{array}{l}\text { IND.1.BP1: Create the vision. The leader envisions a } \\
\text { desirable future condition [Outcome 1] }\end{array}$ \\
& $\begin{array}{l}\text { IND.1.BP2: Communicate the vision. The leader } \\
\text { communicates the vision in a way that creates positive } \\
\text { expectation in the team members [Outcome 2]. }\end{array}$ \\
\hline & $\begin{array}{l}\text { IND.1.BP3: Commitment to vision by team. The leader } \\
\text { obtains commitment from the team members for the } \\
\text { realisation of the vision, making it a shared vision [3]. }\end{array}$ \\
\hline \hline & Work Products / Activities / Conditions \\
\hline \multicolumn{1}{c}{ Inputs } & \\
\hline $\begin{array}{l}\text { Business goals } \\
\text { [Outcome 1] }\end{array}$ & Team Charter [Outcome 1] \\
\hline & Imperative Objectives [Outcome 1] \\
\hline $\begin{array}{l}\text { Customer } \\
\text { requirements } \\
\text { [Outcome 1] }\end{array}$ & Project Plan [Outcome 1] \\
\hline
\end{tabular}

Note that the PAM can be used in three possible ways, (a) by project managers to evaluate their own practice, and engage in self-improvement by benchmarking against best-practice, and (b) by organisations wishing to improve their internal management capability, and (c) theoretically by external agencies wishing to evaluate a potential supplier's management capability (though this would be some distance away since the capability dimension has not been established).

Table 5. Structure and content of PAM Example 2.

\begin{tabular}{|c|c|}
\hline Process ID & IND.2 \\
\hline Process Name: & Objectives \\
\hline Process Purpose: & $\begin{array}{l}\text { The purpose of the objectives process is create and } \\
\text { communicate objective(s) based on the vision and derived } \\
\text { goals. }\end{array}$ \\
\hline \multirow[t]{3}{*}{ Process Outcomes: } & $\begin{array}{l}\text { As a result of successful implementation of the objectives } \\
\text { process: }\end{array}$ \\
\hline & $\begin{array}{l}\text { 1) Practical objective(s) for goal(s) achievement are } \\
\text { developed. }\end{array}$ \\
\hline & $\begin{array}{l}\text { 2) Positive expectation for achieving objective(s) is } \\
\text { encouraged. }\end{array}$ \\
\hline \multirow[t]{2}{*}{ Base Practices: } & $\begin{array}{l}\text { IND.2.BP1: Develop objectives. The leader derives a set } \\
\text { of practically worded objectives from the shared vision and } \\
\text { subsequent goals that give the team a concrete set of } \\
\text { outcomes to achieve. [Outcome 1] }\end{array}$ \\
\hline & $\begin{array}{l}\text { IND.2.BP2: Encourage positive expectation. The leader } \\
\text { generates an optimistic mind-set and outlook in the team } \\
\text { towards the achievement of the objectives [Outcome 2] }\end{array}$ \\
\hline \multicolumn{2}{|r|}{ Work Products / Activities / Conditions } \\
\hline Inputs & Outputs \\
\hline \multirow[t]{2}{*}{$\begin{array}{l}\text { Vision statement } \\
\text { [Outcome 1] }\end{array}$} & Goals [Outcome 1] \\
\hline & Objectives [Outcome 1] \\
\hline \multirow[t]{2}{*}{$\begin{array}{l}\text { Project plan [Outcome } \\
\text { 1] }\end{array}$} & Goals [Outcome 1] \\
\hline & Objectives [Outcome 1] \\
\hline $\begin{array}{l}\text { Project launch } \\
\text { [Outcome 2] }\end{array}$ & Positive expectation re vision [Outcome 2] \\
\hline
\end{tabular}




\begin{tabular}{ll}
\hline $\begin{array}{l}\text { Team briefing [Outcome } \\
\text { 2] }\end{array}$ & Commitment to vision [Outcome 2] \\
\hline $\begin{array}{l}\text { Yearly kick-off } \\
\text { [Outcome 2] }\end{array}$ & Positive expectation re vision [Outcome 2] \\
\hline $\begin{array}{l}\text { Quarterly review } \\
\text { [Outcome 2] }\end{array}$ & Commitment to vision [Outcome 2] \\
\hline
\end{tabular}

\section{Conclusion}

This paper explored the question; can the governance of virtual teams be optimized through the use of Reference Models of Organisational Behavior (RMOB). In our treatment of this main question, two subordinate questions were discussed; (a) might the RMOB thus be a viable option for developing nations to reap the economic benefits of greater participation in the global economy, and (b) to do so in an environmentally sustainable way?

Arguably, RMOBs do have the potential to improve the effectiveness of virtual team governance. In this instance, this is achieved through giving project managers the means to develop their leadership capabilities to a higher level. The RMOB discussed here can be applied in the broadest possible range of project management environments, in both the developed and developing worlds, thus allowing the developing world to participate in global virtual projects to a greater extent. This then delivers a range of economic benefits for developing nations while being environmentally sustainable through reducing the need for team members to travel and so produce carbon dioxide and consume other resources in the course of their travel.

The paper therefore examined the issue of effective governance and leadership in organisations and argues the case that (a) leadership can be learned (as opposed to only having it through inheritance), and which can be formalized into a Process Reference Model, (b) Process Reference Models in the strict sense defined by the relevant ISO/IEC standards can be more broadly redefined to include a new category of PRM called provisionally a Reference Model of Organisational Behavior which focuses on organisational behavior in the pursuit of goals rather than the narrower PRM approach of process and observable outcome, and (c) that such a PRM could have significant implications for organisations seeking to achieve a more sustainable project management approach.

In support of the case that leadership can be learned is the extensive body of work by influential researchers on leadership like Warren Bennis (1994) and Peter Drucker (1996). This does not ignore the innate charisma of so-called 'born leaders', but makes the case that leadership can be understood and applied more effectively in a practical sense.

It is clear that if a "implicit" concept such as Leadership can be re-conceptualized in this manner such that all of its underlying components can be analyzed and explored, then it would be possible to further re-conceptualize other "implicit' concepts within the modern Organization such as Culture, Innovation and Capabilities. These important concepts must be understood if all of the important activities that occur within the modern Organization are to be modeled and managed.

In support of the case that leadership can be described as a process reference model is the work of process pioneer W. Edwards Deming who observed that if you cannot describe what you are doing as a process, you don't really know what you are doing (Deming, 1997). While the Leadership Process Reference Model conforms to the normative reference, qualifying it to be called a PRM, the broader, more organizationally-focused nature of this model suggests it might be best described as a new category of PRM, provisionally called a Reference Model for Organisational Behavior.

A Leadership PRM developed by a rigorous Design Research process and tested in empirical trials and found to be useful by practitioners and experts is arguably a viable model. Strengthening this position is the draft Process Assessment Model that considers initially the process performance dimension, but which will be elaborated in on-going trials for the inclusion of the capability dimension.

The results so far have been encouraging. Not only is a Leadership PRM \& PAM useful its own right, but it also points to the possibility of developing other Reference Models for Organisational 
Behavior and PAMs covering a range of organisational behaviors in a range of disciplines including but not limited to financial institutions and banks, automotive systems and software, aerospace systems and software, medical device systems and software, IT service management, test process improvement, small and very small enterprises. This would significantly extend the breadth of application of the standardized approach to process assessment.

The use of this new category of process reference model, called Reference Model of Organisational Behavior is therefore recommended as an effective method for improving (a) project governance, (b) sustainability of projects in a more non-polluting manner, and (c) equity of access and participation in the global economy of people living in developing and developed areas alike.

\section{Organization of the Text}

Section Headings. The section headings are in boldface capital and lowercase letters. Second level headings are typed as part of the succeeding paragraph (like the subsection heading of this paragraph).

Page Numbers. Do not number your paper:

Tables. Tables (refer with: Table 1, Table 2, ...) should be presented as part of the text, but in such a way as to avoid confusion with the text. A descriptive title should be placed above each table. Units in tables should be given in square brackets [meV]. If square brackets are not available, use curly $\{\mathrm{meV}\}$ or standard brackets $(\mathrm{meV})$.

Special Signs. for example, $\alpha \gamma \mu \Omega() \geq \pm \bullet \Gamma\{11 \overline{2} 0\}$ should always be written in with the fonts Times New Roman or Arial, especially also in the figures and tables.

Macros. Do not use any macros for the figures and tables. (We will not be able to convert such papers into our system)

Language. All text, figures and tables must be in English.

Figures. Figures (refer with: Fig. 1, Fig. 2, ...) also should be presented as part of the text, leaving enough space so that the caption will not be confused with the text. The caption should be self-contained and placed below or beside the figure. Generally, only original drawings or photographic reproductions are acceptable. Only very good photocopies are acceptable. Utmost care must be taken to insert the figures in correct alignment with the text. Half-tone pictures should be in the form of glossy prints. If possible, please include your figures as graphic images in the electronic version. For best quality the pictures should have a resolution of $300 \mathrm{dpi}$ (dots per inch).

Color figures are welcome for the online version of the journal. Generally, these figures will be reduced to black and white for the print version.

\section{Literature References}

References are cited in the text just by square brackets [1]. (If square brackets are not available, slashes may be used instead, e.g. /2/.) Two or more references at a time may be put in one set of brackets $[3,4]$. The references are to be numbered in the order in which they are cited in the text and are to be listed at the end of the contribution under a heading References, see our example below.

\section{Conclusions}

If you follow the "checklist" your paper will conform to the requirements of the publisher and facilitate a problem-free publication process.

\section{Acknowledgements}

This work was financially supported by Griffith University and Macquarie University, Australia. 


\section{References}

[1] Herbsleb, J.D. Moitra, D. (2001) Global Software Development, IEEE Software, Vol 18, Issue 2, (16-20).

[2] Bell, B.S., Kozlowski, S.W. (2002). A Typology of Virtual Teams: Implications for Effective Leadership. Group and Organisational Management, Vol. 27, No.1 pp. 14-19.

[3] Hertela, G., Geisterb, S., Kontrabt, U. (2005) Managing virtual teams: A review of current empirical research. Human Resource Management Review Volume 15, Issue 1, March 2005, Pages 69-95.

[4] Markus, M.L., Manville, B., Agres, C.E., (2000) What Makes a Virtual Organization Work? Sloan Management Review; Vol. 42 Issue 1, p13-26, 14p

[5] Stacey, R Learning as an activity of interdependent people, (2003) The Learning Organization, , No. 6, pp.325-341.

[6] ISO/IEC 15504 (2003). Information Technology: Process Assessment. Joint Technical Committee IT-015, Software and Systems Engineering. This Standard was published on 2 June 2005.

[7] ISO/IEC TR 24774 (2007). Software and systems engineering -- Life cycle management -Guidelines for process description. This Standard was published in 2007.

[8] Argwal, N. Rathod U (2006) Defining success for software projects, International Journal of Project Management, Vol. 24, No. 4, pp.358-370.

[9] ] Garland, R., (2009) Project Governance - a practical guide to effective project decision making, Kogan Page, London, Philadelphia,

[10] Fortune D., White J (2006) Framing of project success factors by a systems model, International Journal of Project Management, Vol. 24, No. 1, pp. 53-65.

[11] Mahdi, I.M. Alreshaid, K. (2005) Decision support system for selecting proper delivery method using analytical hierarchy process, International Journal of Project Management, Vol.23, 7, pp. 564-572.

[12] Drucker, P. (1996) Managing in a Time of Great Change, Butterworth Heinemann, London.

[13] Bennis, W., (1994) On Becoming a Leader, What Leaders Read 1, Perseus Publishing, p 2.

[14] Humphrey, W.S., (2002) Winning with Software. Addison Wesley Longman, Reading Massachusetts.

[15] Repenning, N.P., Sterman, J.D., (1997) Getting Quality the Old-Fashioned Way: Self-Confirming Attributions in the Dynamics of Process Improvement. Sloan School of Management, MIT., Cambridge, MA. (Available at: http://web.mit.edu/jsterman/www/SDG/Attrib.pdf ).

[16] Deming, W.E. (1997), Out of the Crisis, MIT Press, Cambridge MA.

[17] Taylor T and Goldstein R (2010), Sustainable Water Resources Management Sustainable Water Resources Management, Volume 1: Executive Summary. Electric Power Research Institute (EPRI), Palo Alto, CA and WERF, Alexandria, VA: 2010. 1019582

[18] Newell, A. Simon, H. A. (1973) Human Problem Solving, Prentice Hall, NY: USA.

[19] Checkland, P.B. (1981) Systems Thinking, Systems Practice, John Wiley, UK, pp.61-65.

[20] Linstone, H (1999) Decision Making for Technology Executives: Using Multiple Perspectives to Improve Performance, Artech House Publisher, USA. 
[21] Rosenhead, J. (1996) 'What's the problem? An introduction to problem structuring methods', Interfaces, vol.26, no, 6, pp.117-131.

[22] Heston, K.M, Phifer, W, (2009)The Multiple Quality Models Paradox: How Much 'Best Practice' is Just Enough? Software Process Improvement and Practice. Wiley InterScience.

[23] Hevner, A., March, S., Park, J. and Ram, S. (2004). Design Science in Information Systems Research. MIS Quarterly 28(1): pp 75-105.

[24] Hevner, A. (2007). A Three Cycle View of Design Science Research. Scandinavian Journal of Information Systems, 10(2) pp87-92.

[25] Dromey, R.G. (2006) Climbing Over the 'No Silver Bullet' Brick Wall, IEEE Software, Vol. 23, No. 2, pp.118-120.

[26] Tuffley, D., Rout, T, (2009) Applying Behavior Engineering To Process Modeling, in Proceedings of the 1st Improving Systems and Software Engineering Conference (ISSEC), National Convention Centre, Canberra, Australia, 10-12 August 2009.

[27] Vaishnavi, V.K., Kuechler, W. (2007) Design Science Research Methods and Patterns: Innovating Information and Communication Technology. CRC Press.

[28] Takeda, H., Veerkamp, P., Tomiyama, T., Yoshikawam, H. (1990). Modeling Design Processes. AI Magazine Winter: pp 37-48.

[29] OECD, (2009) Sustainable Governance Indicators 2009. Policy Performance and Executive Capacity. p. 22. 